\title{
TRANSFER OF THE RADIAL NERVE BRANCHES FOR THE TREATMENT OF THE ANTERIOR INTEROSSEOUS NERVE LESION: AN ANATOMICAL STUDY
}

\author{
TRANSFERÊNCIA DOS RAMOS DO NERVO RADIAL PARA \\ TRATAMENTO DA LESÃO DO NERVO INTERÓSSEO \\ ANTERIOR: ESTUDO ANATÔMICO
}

\author{
Fernando César Matavelli Júnior ${ }^{1}$, LuCas Gobb ${ }^{1}$, Marcos Paulo Sales dos Santos ${ }^{1}$, Edie Benedito Caetano ${ }^{2}$, \\ LUIZ ANGELO VIEIRA ${ }^{2}$, RENATO ALVES DE ANDRADE ${ }^{1}$
}

1. Pontifícia Universidade Católica de São Paulo, Faculdade de Ciências Médicas e da Saúde, São Paulo, Brazil.

2. Pontifícia Universidade Católica de São Paulo, Faculdade de Ciências Médicas e da Saúde, Departamento de Cirurgia, São Paulo, Brazil.

\section{ABSTRACT}

Objective: This anatomical study aimed to analyze the possibility of transferring the radial nerve branches destined to the brachioradialis (BR), extensor carpi radialis longus (ECRL), extensor carpi radialis brevis (ECRB), and supinator (SM) muscles to innervate the AIN. Methods: Ten limbs from five male cadavers were prepared by intra-arterial injection of a solution of $10 \%$ glycerol and formalin. Results: The presence of only one branch to the BR muscle was noted in 7 limbs and two branches were noted in three limbs. In two members of a common trunk with branch to the ECRL. In eight cases, we identified one branch for the ERLC and two branches in two cases. We identified only one branch for the ECRB, while in six limbs, two branches were noted, penetrating the muscular body at two different points. We identified at least two branches innervating the supinator muscle. The AIN was detached from the median nerve distal to the intercondylar line of the humerus. In seven limbs, it originated from the nervous fascicles of the posterior region of the median nerve and from the posterolateral fascicles in three limbs. The flexor pollicis longus and flexor digitorum profundus muscles received more than one branch of the AIN in all limbs. Conclusion: The radial nerve branches for the ECRL, ECRB, and supinator muscles can be transferred directly to the AIN or to one of its branches after intraneural dissection, without tension even in elbow movements. Level of Evidence IV; Case series.

Keywords: Radial nerve. Median nerve. Nerve transfer. Cadaver. Anatomy.

\section{RESUMO}

Objetivo: Analisar a possibilidade de transferir os ramos do nervo radial (NR) destinados aos músculos braquiorradial (BR), extensor radial longo do carpo (LREC), extensor radial curto do carpo (ERCC) e supinador (SM) para reinervar o nervo interósseo anterior (NIA). Métodos: Estudo anatômico, no qual foram dissecados dez membros de cinco cadáveres preparados com solução de glicerina e formol a 10\%. Resultados: A presença de apenas um ramo para o músculo BR foi registrada em sete membros e de dois ramos em três membros. Em dois membros de um tronco comum com ramo para o ERLC. Em oito membros, identificamos um ramo para o ERLC e, em dois membros, dois ramos. Identificamos apenas um ramo para o ECRB, este em seis membros, se dividia em dois ramos. Ainda, identificamos pelo menos dois ramos para o SM. Em sete membros, originou-se dos fascículos nervosos da região posterior do MN e, em três membros, dos fascículos posterolaterais. Os músculos flexores longo do polegar (FLP) e profundo dos dedos (FPD) receberam mais que um ramo do NIA em todos os membros. Conclusão: Os ramos do NR destinados aos músculos $B R$, ERLC, ECRB e SM podem ser transferidos ao NIA ou a um de seus ramos, sem tensão mesmo durante a movimentação do cotovelo. Nível de Evidência IV, Série de casos.

Descritores: Nervo Radial. Nervo Mediano. Transferência de Nervo. Cadáver. Anatomia.

Citation: Matavelli Jr FC, Gobbi L, Santos MPS, Caetano EB, Vieira LA, Andrade RA. Transfer of the radial nerve branches for the treatment of the anterior interosseous nerve lesion: an anatomical study. Acta Ortop Bras. [online]. 2019;27(6):298-303. Available from URL: http://www.scielo.br/aob.

\section{INTRODUCTION}

The anterior interosseous nerve (AIN) is originated from the median nerve $(\mathrm{MN})$ in variable place. In its origin it is initially located parallel to $\mathrm{MN}$, lower it is located between the laterally long flexor of the thumb (LFT) and the deep medially flexor of the fingers, sending branches to both of these muscles. It has constant branches to the deep flexor of the index finger and provides partially the deep flexor of the medium finger. The deep flexor of the other fingers is provided

All authors declare no potential conflict of interest related to this article.

The study was conducted at Faculdade de Ciências Médicas e da Saúde. Pontifícia Universidade Católica de São Paulo.

Correspondence: Edie Benedito Caetano. Departamento de Cirurgia. Faculdade de Ciências Médicas e da Saúde. Pontifícia Universidade Católica de São Paulo. Rua Joubert Wey, 290, Sorocaba, São Paulo, Brazil. 18030-070. ediecaetano@hotmail.com 
by the ulnar finger. The AIN, after emitting the branches to FDP and LFT, follows along with the anterior interosseous artery, supporting itself on the anterior aspect of the interosseous membrane, distally innervating the square pronator muscle (SP), sending sensitive branches to the articulations of the carpus. ${ }^{1}$ However, there are considerable variations about the proportion that the $\mathrm{MN}$ and $\mathrm{NU}$ provide to FDP. ${ }^{1-3}$ High injuries of MN happen closely to the origin of AIN, resulting in an inability of the thumb flexion and forefinger with decrease of the muscular force of forceps and grip.

The primary reparation of a nervous injury provides the best function results. Autologous nerve grafts may be employed when the distance between the nerve stumps does not allow nerve suturing without tension. Nevertheless, there are injuries of nervous which are not able for primary repair and to which the grafts does not allow satisfactory results. These injuries include very proximal nerve injury; extensive injury zone, resulting in a long space between nerve stumps; and idiopathic nerve paralysis or neuritis in which there is no healthy proximal nerve segment. ${ }^{4,5}$

In case of high injuries of $\mathrm{MN}$, with very long intervals between the extremities, it may not have enough time to generate the axon and so get the terminal motor places of the nervous muscles by $\mathrm{AIN}<$ before they become permanently resistant to the reinnervation. This long period of denervation let LFT and FDP muscles able to irreversible denegation of the fibrosis of the terminal motor plates. ${ }^{4-6}$ In the distais, the time of reinnervation is minimized by the proximity with the motor plate. The donator nervous must be dispensable or redundant, must have pure motor fibers, diameter and number of compatible axons, and most preferably innervate synergistic muscles to the receptor. ${ }^{7}$ The understading of brain plasticity and the potential of motor reeducation insentivated the developing of these techniques. ${ }^{8,9}$

Some authors have recommended that branches of the radial nerve $(\mathrm{RN})$ for the muscles: brachioradialis $(\mathrm{BR})$, radial extensor long of the carpi (ERLC), short radial carpal extensor (ECRB) and branches to supinator muscle (SM) were transferred to the nerve AIN.10-14 Good functional results have been reported from clinical series of nerve transfer from RN branches to AIN in high MN lesions and in certain brachial plexus lesions. In spite of encouraging clinical reports, few anatomical studies have been conducted about this. The objective of this study was to evaluate in members of corpses the advantages and disadvantages of each one of the RN branches destined to the BR, ERLC, ECRB muscles, and branches to the SM to be transferred to the NIA. We considered the number of branches, fiber nature, muscle function, availability of the donor, synergistic relationships, diameter and number of myelinated fibers, and how close to the target muscles the transfer can be performed without tension even with elbow mobilization.

\section{METHODS}

Ten members of 5 corpses were dissected, all adults and males, were prepared by intra-arterial injection of a $10 \%$ glycerol and formalin solution. The cadavers did not present evidence of deformities, previous surgical procedures or traumatic injuries in the studied area. We removed the skin and fascia from the third distal of the arm, forearm and wrist. MN was identified in the arm and dissected from proximal to distal. The bicipital aponeurosis was sectioned. The round pronator muscle (RP) was disinserted distally and put apart. Tendons of the flexor radial carpal (FRC) and long palmar muscles (LP) were sectioned in the third distal to make the identification of their nerve branches easier. The branches of MN destined for the muscles: RP, RFC, LP, FSD (superficial flexor of the fingers) and AIN with their branches destined to FPD, LFT and $P Q$ were dissected after the longitudinal division of the FSD and its fibrous arch, following the AIN in the forearm from proximal to distal. RN was identified in the arm between the brachial (MB) and BR muscles and dissected from proximal to distal. The tendons of the BR, ERLC and ECRB muscles were sectioned in their third distal, separated from the fibrous connections that bonded them to facilitate identification of the nerve branches. The division of the RN into its branches: posterior interosseous nerve (PIN) and superficial branch of the radial nerve (SBRN) was identified and related to the humeral intercondylar line $(\mathrm{HIL})$.

The destined branches for the BR, ERLC, ECRB, SM and NIP muscles were dissected. Vascular structures have not been preserved to make the dissection of the nerves easier. In certain phases of the dissection we used a 2.5 magnifying glass. The distance between the LIU was analyzed both with the radial nerve dividing point, as well as with the radial nerve emergence point in the arm, between MB and BR. The order of innervation and the number of branches were recorded with a digital caliper and a millimeter ruler, we measured the diameter and length of the branch for the muscles BR, ERLC, ECRB, NIP, branches for SM. The diameter of the nerves was measured at the midpoint of their length. We analyzed the advantages and disadvantages of each branch of the RN to be transferred to the AIN. We considered the number of branches, fiber nature, muscle function, donor availability, synergistic relationships, diameter, number of myelinated fibers and how close to the target muscles the transfer can be performed without tension. All measurements were performed during the procedures, directly on the anatomical pieces. This work was approved by the Ethics Committee with the number 2.207.258.

\section{RESULTS}

$\mathrm{RN}$ crossed the lateral intermuscular septum between the MB and BR muscles, on average $9.5(8.5$ to $10.5 \mathrm{~cm})$ proximal to LIU. The first RN branch in the elbow region went to the BR muscle. The presence of only one branch to the BR muscle was recorded in 7 limbs, two branches in 3 limbs. In two limbs of a common trunk with branch to ERLC. The second branch went to ERLC. In 8 limbs we identified a branch for the ERLC, in two members, two branches. We identified only one branch for the ECRB, this one with 6 limbs, this one was divided in two branches, penetrating in the muscular body in two different points. We identified at least two branches for SM, which were originated from NIP. The length and diameter of RN branches are described in Table 1.

The AIN detached from the MN at a distance of $5.7 \mathrm{~cm}(2.0$ to $7.8 \mathrm{~cm})$, distal to the intercondylar line of the humerus. In 7 limbs it originated itself from the nervous fascicles of the posterior region of the MN and in 3 members of the posterolateral fascicles.

The interosseous nerve detached itself from the MN proximally to the RP muscle in 3 limbs, distally to it in $1 \mathrm{limb}$. In 6 limbs it detached itself from MN under the RP muscle mass.

In all the dissected limbs we recorded that the AIN detached from the MN proximally to the arcade formed between the insertions of

Table 1. Average length and diameters of donor nerves and receptor nerves.

\begin{tabular}{c|c|c|c|c}
\hline & Libs & $\begin{array}{c}\text { Lenght Average } \\
\text { in } \mathbf{~ m m}\end{array}$ & $\begin{array}{c}\text { Lenght average } \\
\text { in } \mathbf{~ m m}\end{array}$ & $\begin{array}{c}\text { Myelinated number } \\
\text { and axons }\end{array}$ \\
\hline BR & 10 & $3,20,8$ & $1,70,6$ & 55064 \\
\hline LREC & 10 & $3,21,0$ & $1,80,5$ & $-\cdots-\cdots---$ \\
\hline DCRE & 10 & $4,52,5$ & 1,506 & 548175 \\
\hline SM & 10 & $2,01,2$ & $1,60,7$ & 545101 \\
\hline AIN & 10 & $5,22,7$ & $2,00,9$ & 2266274 \\
\hline
\end{tabular}

BM - brachioradiali muscle; LREC - extensor radial curto do carpo; ECRB- extensor radial curto do carpo; SM - supinator muscle; AIN - anterior interosseous nerve. 
the FSD. We analyzed the number of branches destined for the LFT and FPD muscles that penetrated in different points of their muscle mass. The presence of two branches for the FPD and one for the LFT in 3 limbs, 2 branches for each muscle in 3 limbs, 3 for the FPD and 1 for the LFT in 2 members, 3 for the FPD and 2 for the FSD in 2 limbs. The longest branch was always destined to LFT (Table 2).

The advantages and disadvantages of each of the RN branches destined for the BR, ERLC, ECRB were analyzed and also branches for SM to be transferred to the AIN. The AIN nerve fibers were put apart from the MN to allow tension-free nerve co-optation. Thus, the nervous connections were possible in all the members.

Table 2. Average of the numbers of AIN braches to FLP and DFF.

\begin{tabular}{c|c|c}
\hline Number of specimens & Branches to the lft & Branches to the DFF \\
\hline 3 & 1 & 2 \\
\hline 3 & 2 & 2 \\
\hline 2 & 1 & 3 \\
\hline 2 & 2 & 3 \\
\hline
\end{tabular}

AIN - anterior interosseous nerve; FLP - long flexor of thumb; DFF - deep flexor of fingers

\section{DISCUSSION}

Traditionally, in the irreparable injuries of MN, the digital flexion has been repaired by tendon transferences. For example: Tendon transfer of the ERLC muscle to the FPD muscle and tendon BR to the LFT. Nervous transference from $\mathrm{RN}$ branches for the reconstruction of the flexion of the fingers has been described in the literature. Garcia Lopes et al. ${ }^{10}$ report advantages of nerve transfer over tendinous transfer: 1- the appropriate trajectory of the tendon is maintained; 2 - the transfer of nerves requires a less extensive surgical exposure; 3 - the good passive mobility of the wrist is not a prerequisite; 4 - the movement of flexion and extension of the fingers is much more independent and natural in the nerves transference than in the transfers of tendons. The disadvantage of nervous transferences is the waiting period for nerve growth.

Hsiao et al..$^{15}$ transferred SM branches to the AIN. Murphy et al. ${ }^{12}$ transferred SM branches combined with the ECRB muscle branch for the NIA. García-López et al. ${ }^{10}$ reported the transfer of the nerve branch of the BR muscle to the AIN. Bertelli ${ }^{11}$ transferred the ECRB branch to the NIA. In another article they reported the distal branch transfer from the ECRB to the LFT.13

We evaluated the advantages and disadvantages of possible RN branch transfers to restore flexion of the fingers in MN lesions. (Figure 1) We considered the number of branches, fiber nature, muscle function, donor availability, synergistic relationships, diameter and number of myelinated fibers.

\section{Transfer of the BR muscle motor branch to the AIN:}

Advantages: 1- The branch to the BR muscle is made up of motor fibers only. It is an accessory flexor of the elbow, helps supination when the forearm is at maximum pronation, and has little importance for elbow flexion, its denervation does not significantly alter these functions. ${ }^{10}$ - The presence of more than one branch of the radial nerve for BR has been found frequently, ${ }^{16,17}$ thus one of the branches is preserved maintaining its innervation. The donor and receiver nerves are long enough for transfer. The average diameter of the AIN was $2.0 \pm 0.9 \mathrm{~mm}$ and the branch diameter for the BR muscle $1.7 \pm 0.6$, which correspond to $85 \%$ allowing a compatible cooptation. We reproduced this neurotization in 10 limbs of 5 corpses and observed that the transfer of the motor branch of the BR muscle to the AIN was possible in all limbs. The AIN fibers were separated from $\mathrm{MN}$ to the cubital fossa, thus allowing direct co-optation of the nerves (Figura 2).

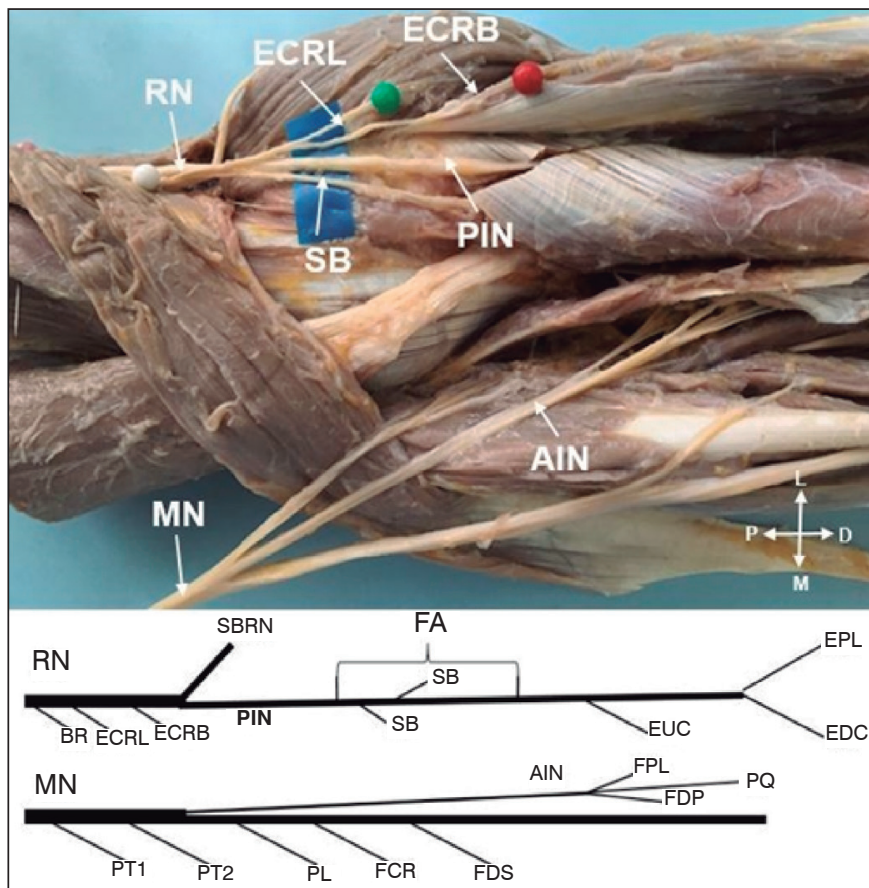

Radial nerve (NR); median nerve (MN); anterior interosseous nerve (AIN), branch to the brachioradialis (BR); branch to the long radial carpal extensor (LREC); branch to extensor carpi radialis brevis (ECRB), branch to the supinator (SB); Froshe arcade; branch to the ulnar carpal extensor (UCE); branch to the long extensor of the thumb (LET); branch to common finger extensor (CEF). Branches to the round pronator (RP); branch to long palmar (PL); branch to flexor of the carpus (RFC); branch to superficial flexor of the fingers (FSD); anterior interosseous nerve (AIN); branch to long flexor of the thumb (FLP); branch to deep flexor of the fingers (DFF).

Figure 1. Transfer of branches of the radial nerve $(\mathrm{RN})$ to reinnervate the anterior interosseous nerve (AIN)

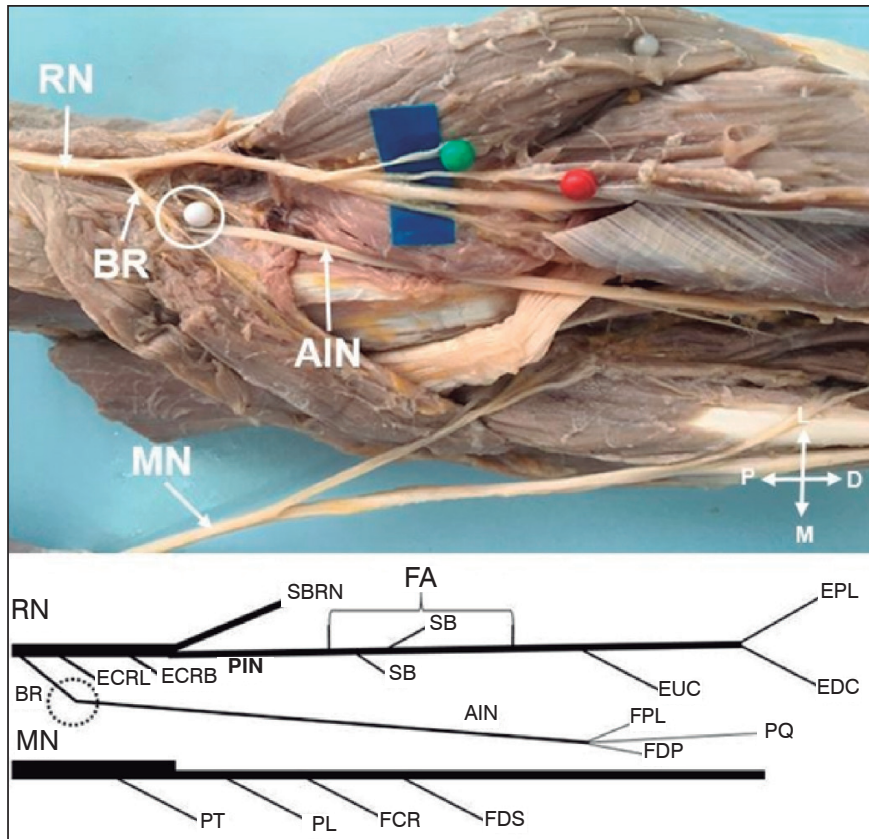

Radial nerve (RN); median nerve (MN); anterior interosseous nerve (AIN), branch to the brachioradialis (BR), branch to the radial extensor for carpus (LREC), branch to extensor carpi radialis brevis (ECRB), branch to supinator (SB). Froshe arcade; branch for the ulnar extensor of the carpus (UCE), branch to the long extensor of the thumb (LET), branch to common extensor of fingers (CEF). Branch to round pronator (RP); branch to long palmar (LP); branch to flexor of the carpus (RFC); branch to flexor of the fingers (FSD); anterior interosseous nerve (AIN); branch to flexor of the thumb (FLP); branch to deep flexor of the fingers (DFF).

Figure 2. Transfer of the branch of the brachioradialis (BR) to reinnervate the anterior interosseous nerve (AIN) 
Disadvantages: The BR muscle has potential to be used in tendinous transfers, and its major indication is the transfer to the LFT tendon. ${ }^{10}$ The average of myelinated BR axons was 550 and the AIN was 2266 myelinated axons, ${ }^{10}$ therefore, the myelinated fibers for the BR muscle corresponded to only $24.3 \%$ of those of the AIN. ${ }^{10}$ Schereiber et al. ${ }^{18}$ consider that the number of myelinated fibers in the donor nerve should be at least $70 \%$ of the number of the receptor nerve. In contrast De Medinaceli ${ }^{19}$ believed that reinnervation of $30 \%$ of muscle fibers is compatible with normal muscle function. Jiang et al. ${ }^{20}$ report that axons in the proximal stump can multiply themselves by increasing their number by 3 to 4 times.

\section{Transfer of the branch to the ERLC muscle for AIN}

Advantages: 1- It is a pure motor nerve. 2 - It originates distally in relation to the $\mathrm{BR}$ and can be connected with greater proximity to the AIN. 3 - Being essentially a wrist extensor is more easily tested when compared to BR. 4- It frequently presents more than one branch, so one of the branches is preserved after the transfer. ${ }^{16,17}$ 5- It has synergistic relationships with the flexors of the fingers; the extension of the wrist increases the passive tension of the flexors of the fingers and, as a result, causes the flexion of the fingers, increasing the flexion force. Donor nerves with synergistic functions to the receptor nerves facilitate cortical integration. ${ }^{5,8} 6$ - The ECRB muscles and Ulnar extensor of carpi can extend the wrist without radial or ulnar deviation. 7- The average diameter of the AIN was $2.0 \pm 0.9 \mathrm{~mm}$ and the branch diameter for the ERLC muscle $1.8 \pm 0.5$, in the $90 \%$ correspondence case, allowing a compatible co-optation. 8- We reproduced this neurotization in $10 \mathrm{limbs}$ of 5 corpses. We observed that the transfer of the motor branch of the ERLC muscle to the AIN was possible in all limbs. The AIN fibers were separated from $\mathrm{MN}$ to the cubital fossa, therefore making it possible direct co-optation of the nerves (Figure 3).

Disadvantages: 1- It is potentially enough to be used in tendinous transfers, and its major indication is the transfer to the FPD muscle. 2- We did not identify in the literature any reference regarding myelinated fiber counts and the possibility of transferring the ERLC branch to MN branches.

Transfer of the branch to the short radial carpal extensor muscle for AIN:

Advantages: 1- It is a pure motor branch. 2 - It originates distally in relation to $B R$ and ERLC and can be connected with greater proximity to the AIN. 3 - It is the longest of the branches of the radial in the region of the elbow with length of $4,5 \pm 2,5 \mathrm{~cm}$. 4 - As long as it is essentially a wrist extensor, it is easily tested. 5- It has synergistic relationships with the flexors of the fingers. 6 - Its average diameter is $1.5 \pm 06$ and the AIN $2.0 \pm$, 09 corresponds, therefore, to $75 \%$ allowing a compatible cooptation; 7 - In $50 \%$ of the limbs the distance between two motor points (penetration points in the muscle mass) was greater than $3 \mathrm{~cm}$, allowing only its distal branch to be used as a donor, preserving its proximal motor branch, thus, the extension of the wrist can be maintained after transfer by hypertrophy of the remaining innervated portion of the muscle or even by reinnervation of the distal portion of the ECRB by sprouts from adjacent zones, that is, reinnervation by adoption. ${ }^{21}$ We reproduced this neurotization in 10 limbs of 5 corpses. We observed that the transfer of the motor branch of the ERCC muscle to the AIN was possible in all limbs. The AIN fibers were separated from the MN, so allowing direct co-optation of the nerves. (Figure 4)

Disadvantages: 1- It has potential to be used in tendinous transfers and its major indication is the transfer to DFF or RP tendon. ${ }^{15} 2$ Contains an average of 545 myelinated axons, which correspond to $24 \%$ of the number of axons of the AIN. In the case of only one ERCC branch, this percentage would be even lower.

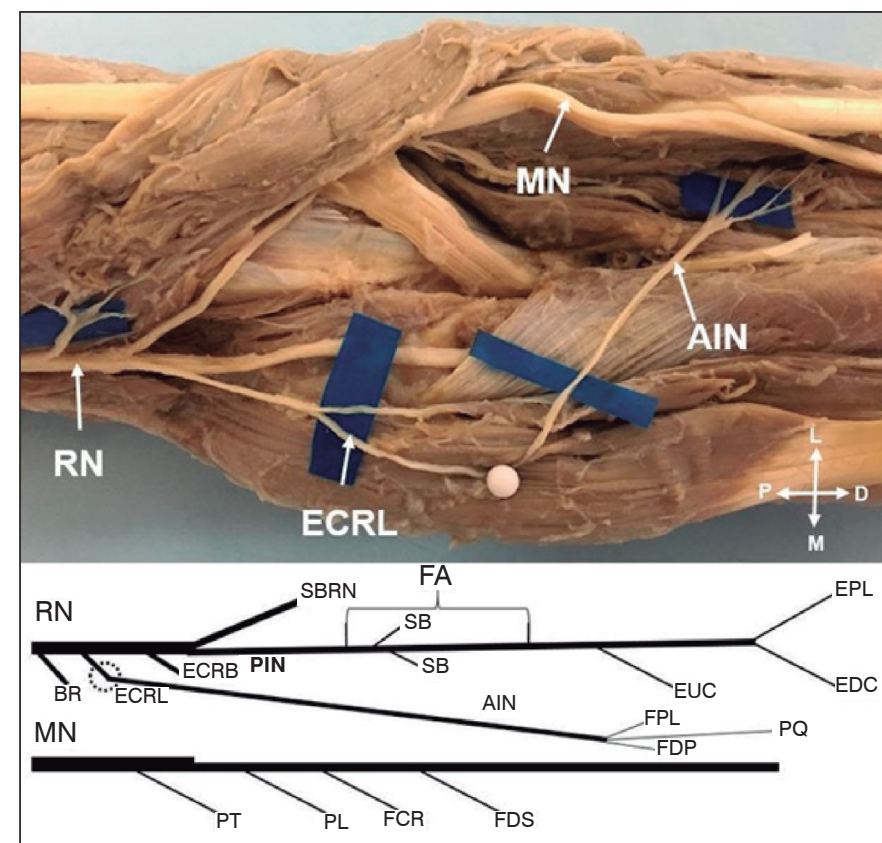

Radial nerve (RN); median nerve (MN); anterior interosseous nerve (AIN), branch to the brachioradialis (BR); branch to the long radial carpal extensor (LREC); branch to extensor carpi radialis brevis (ECRB); branch to the supinator (SB); Froshe arcade; branch to the ulnar carpal extensor (UCE); branch for the long extensor of the thumb (LET); branch to common finger extensor (CEF). Branches for the round pronator (RP); branch for long palmar (PL); branch for radial flexor of the carpus (RFC); branch for superficial flexor of the fingers (FSD); anterior interosseous nerve (AIN); branch to flexor of the thumb (FLP); branch to deep flexor of the fingers (DFF).

Figure 3. Transfer of the branch of the long radial extensor of the carpus (LREC) to reinnervate the anterior interosseous nerve (AIN).

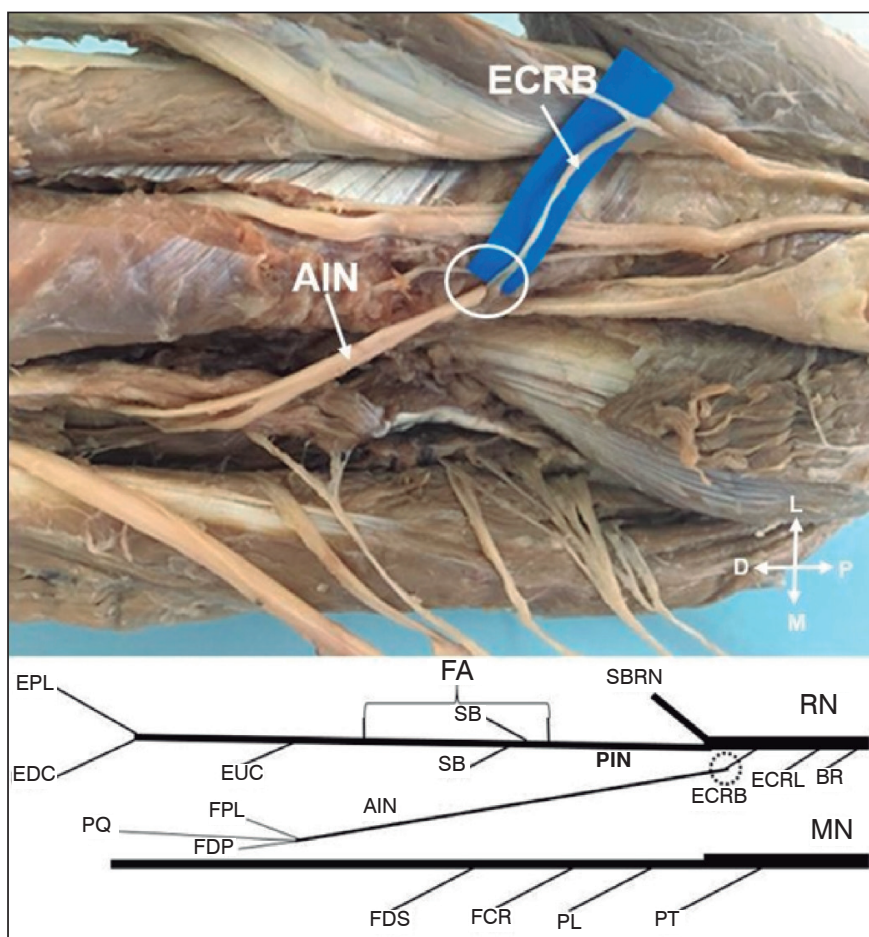

Radial nerve (RN): median nerve (MN): anterior interosseous nerve (AIN), branch to the brachiRadial nerve (RN); median nerve (MN); anterior interosseous nerve (AIN), branch to the brachiradialis brevis (ECRB), branch to the supinator (SB); Froshe arcade; branch to the ulnar carpal extensor (UCE); branch for the long extensor of the thumb (LET); branch to common finger extensor (CEF). Branches for the round pronator(RP); branch for long palmar (PL); branch to radial flexor of the carpus (RFC); branch to superficial flexor of the fingers (FSD); anterior interosseous nerve (AIN); branch to long flexor of the thumb (FLP; branch for deep flexor of the fingers (DFF).

Figure 4. Radial carpal extensor branch transfer of the carpus (ERCC) to reinnervate the anterior interosseous nerve (AIN). 


\section{Transfer of supinator muscle branches to AIN:}

Advantages: 1- Pure motor branch. 2- In all limbs we have identified at least two branches for supinator. 3 - It originates from the NIP, distally in relation to the branches for BR, LREC and ERCC and may be connected with greater proximity to the AIN. Supination can be maintained by the action of the biceps brachial. 4- Due to its anatomical characteristics, it is not used for tendinous transfers. 5 - The average diameter of the AIN was $2.0 \pm 0.9 \mathrm{~mm}$ and the added diameter of the branches to the supinator muscle $1.6 \pm 0.7$, in the corresponding case of $80 \%$ allowing a compatible cooptation. We reproduced this neurotization in 10 limbs of 5 corpses. We observed that the transfer of the motor branch of the muscle ERCC to AIN was possible in all cases. The fibers of AIN were separated from $\mathrm{MN}$, allowing direct co-optation of the nerves. (Figure 5)

Disadvantages: - 1 - There is not synergistic relationship with the flexors of the fingers. 2- Difficult to be tested clinically. 3- Greater difficulty in dissection, it is necessary to section the superficial head of the supinator muscle, to identify its branches. 4- The number of myelinated axons added to SM is 545, which corresponds to only $25 \%$, of the number of myelinated axons of the AIN.

Combined BR branch transfer for AIN branches aimed to DFF and ECRB branch for LFT

Advantages: 1- They are motor branches 2- The sum of the diameter of the donors is 3.2, surpassing the AIN diameter. 3- The sum of numbers of axons myelinated of the nerves for BR and ERCC is 1100 , which corresponds to $48 \%$ of the number of axons the receptor nerve. 4- We reproduced this neurotization in 10 limbs of 5 corpses. We observed that the combined transfer of the BR branch to the
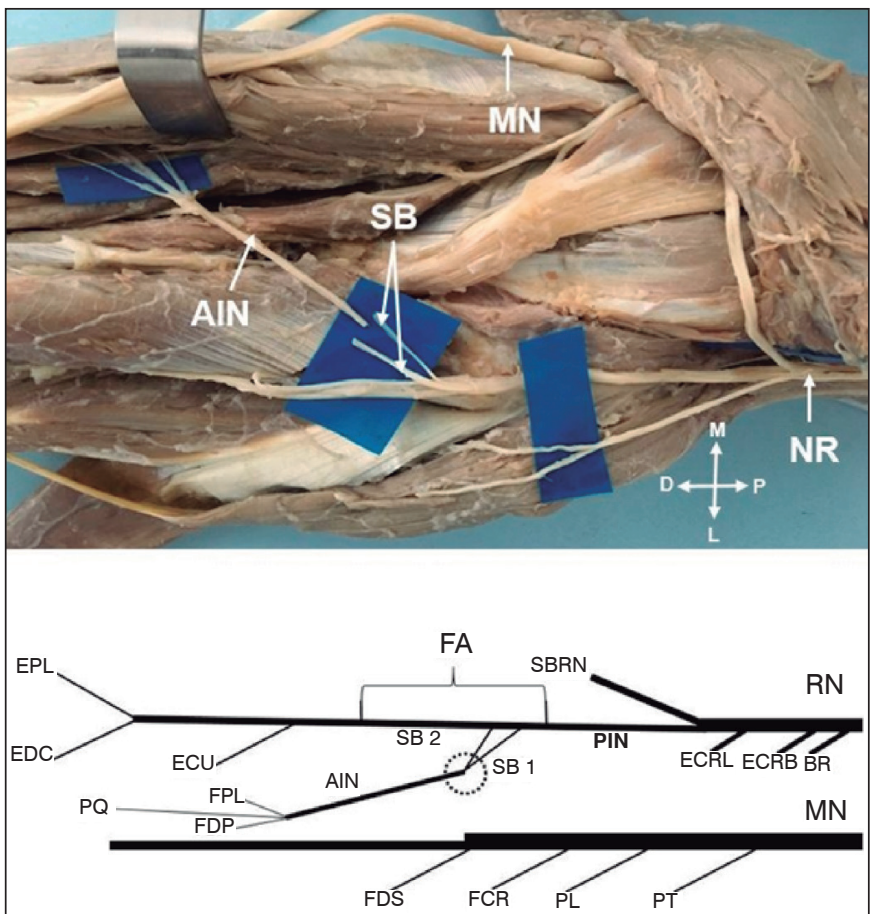

Radial nerve (RN); median nerve (MN); anterior interosseous nerve (AIN), branch to the brachioradialis (BR); branch to the long radial extensor for carpus (LREC), branch to extensor carpi radialis brevis (ECRB), branch to the supinator (RS), Froshe arcade, branch to the ulnar carpal radialis brevis (ECRB), branch to the supinator (RS), Froshe arcade, branch to the ulnar carpal
extensor (UCE), branch to the long extensor of the thumb (LET); branch to common extensor of the fingers (CEF). Branches to round pronator (RP); long palmar branch (PL); branch to radial flexor of the carpus (RFC), branch to flexor of the fingers (FSD); anterior interosseous nerve (AIN branch to long flexor of the thumb (FLP); branch to deep flexor of the fingers (DFF).

Figure 5. Transfer of the branches of the supinator (SB), to reinerve the anterior interosseous nerve (AIN). branches of the AIN destined for the DFF and branch of the ERCC to the AIN was possible in all limbs. The AIN fibers were separated from MN to the cubital fossa, which allowed direct co-optation of the nerves. (Figure 6)

Disadvantages: 1 - They are two muscles that have potential to be used in tendinous transfers. 2 - The intraneural dissection of the AIN separating branches into the FLP and DFF may cause damage to axons of the receptor nerve. 3- The synergism between donor and receiver is only partial.

Combined transfer of the ECRB branches to the AIN branches aimed to LFT and supinator branch for DFF

Advantages: 1- They are motor branches; 2- The sum of donor diameter is 3.1, exceeding the diameter of the receiver. 3- The sum of numbers of axons myelinated of the nerves for ERCC and supinator is 1090 , which corresponds to $48 \%$ of the number of axons of the receptor nerve. 4- The supinator muscle has no potential for tendon transfer. We reproduced this neurotization in $10 \mathrm{limbs}$ of 5 cadavers. We observed that the combined transfer from the ERCC branch to the AIN branches destined for the DFF and branches from the supinator to the AIN was possible in all members. The AIN fibers were separated from the MN, allowing direct co-optation of the nerves (Figure 7).

Disadvantages: 1 - the ERCC muscle has potential to be used in tendinous transfers. 2 - The intraneural dissection of the AIN separating branches to the FLP and DFF, may cause damage to axons of the receptor nerve. 3- The synergism between donor and receiver is only partial.

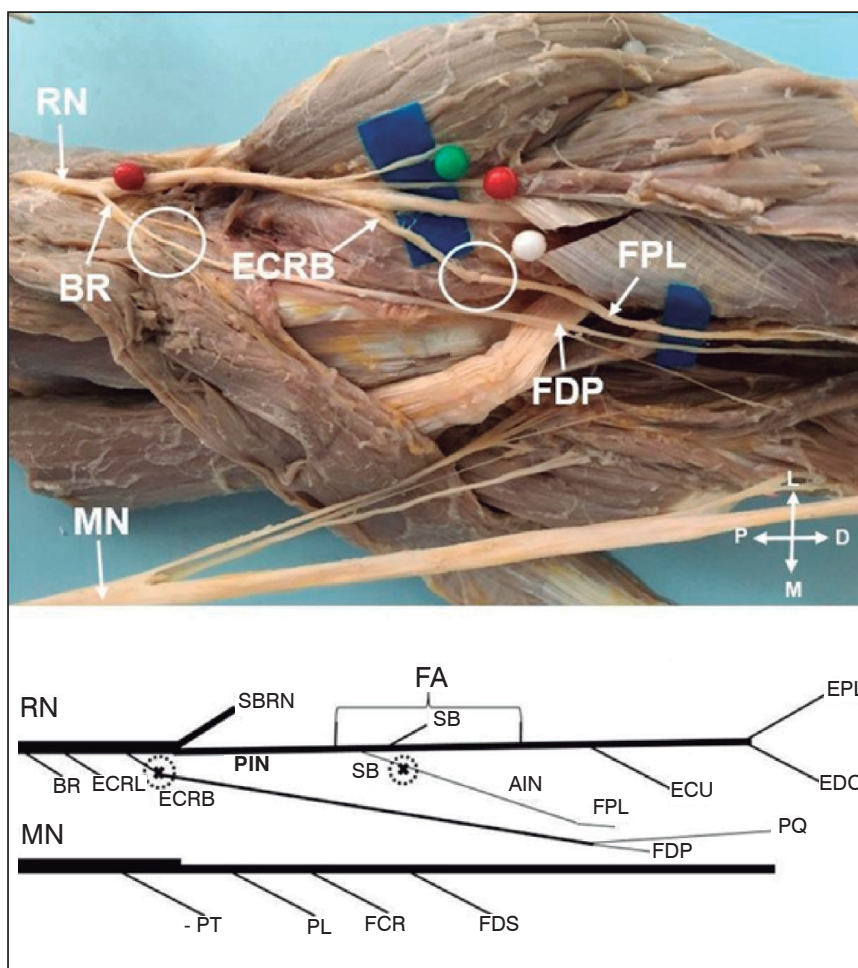

Radial nerve (RN); median nerve (MN); anterior interosseous nerve (AIN), branch to the brachioradialis (BR); branch to the long radial extensor for carpus (LREC), branch to extensor carpi radialis brevis (ECRB), branch to the supinator (RS), Froshe arcade, branch to the ulnar carpal extensor (UCE), branch to the long extensor of the thumb (LET); branch to common extensor of the fingers (CEF); branches to round pronator (RP); long palmar branch (PL), branch to radial flexor of the carpus (RFC), branch to superficial flexor of the fingers (FSD); anterior interosseous nerve (AIN); branch to long flexor of the thumb (FLP); branch to deep flexor of the fingers (DFF).

Figure 6. Transfer of the branch of the brachioradialis to reinerve the deep flexor of the fingers and branch of the short radial extensor of the carpus to reinerve the long flexor of the thumb. 


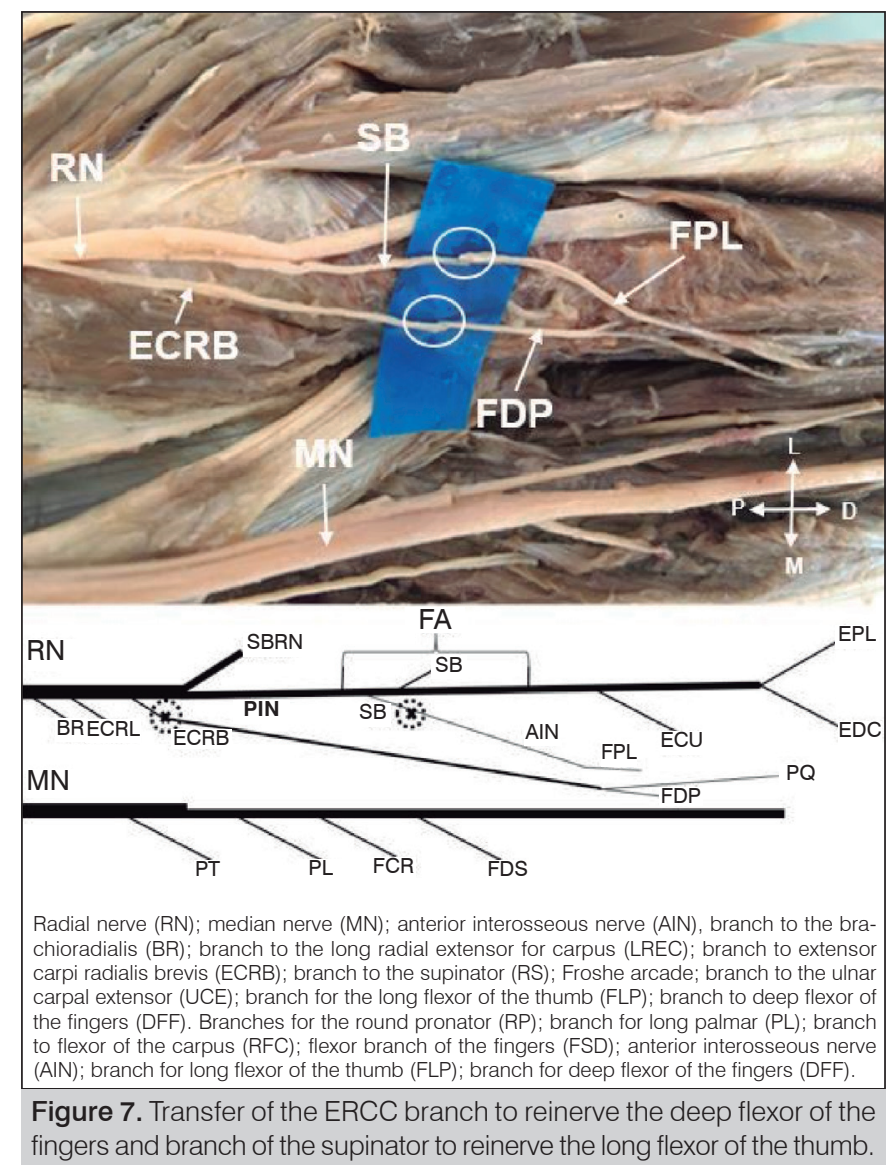

We suggest that surgical approach of the branches of the radial nerve in the elbow region can be done with the forearm in pronation. Incision approximately $13 \mathrm{~cm}$ of length, starting from a point three centimeters proximal to the lateral epicondyle following the axis of the radius. The fascia is incised in the distal region of the arm and forearm and the space between the MB and BR is identified. Deepening the dissection in this space allows NR identification with the branches for the MB, BR, LREC and ERCC. More distally, the space between the short radial extensor carpi (ERCC) and the common extensor of the fingers (CEF) is identified. The dissection is deepened in this space, identifying the SM and the Frohse arcade.

The NIP, proximally the Froshe arcade, can be identified by palpation against the radial diaphysis. The superficial head of the SM must be sectioned, following the path of the NIP, thus exposing the intramuscular portion of the NIP and the branches destined to the SM. Limitations of this study include a limited number of corpses limbs, therefore, statistical analyzes could not be performed.

\section{CONCLUSION}

We analyzed the advantages and disadvantages of each of the RN branches to be transferred to the AIN. We considered the number of branches, fiber nature, muscle function, donor availability, synergistic relationships, diameter, number of myelinated fibers and how close to the target muscles the transfer can be performed without tension. The RN branches destined to the BR, LREC, ERCC, and SM muscles can be transferred directly to the AIN or to one of its branches after the intraneural dissection of these without tension even during the movement of the elbow.

AUTHORS' CONTRIBUTIONS: Each author has significantly contributed to this article. EBC (0000-0003-4572-3854)* e LAV (0000-0003-4406-2492)*: writing of the manuscript, statistical analysis of the data, and intellectual concept of the manuscript and development of the research project. FCMJ (0000-0002-04255700)* LG (0000-0001-9111-0544)* e MPSS (0000-0001-7085-5715)*: data collection, data analysis, manuscript writing and revision. LAV: data collection and analysis. RAA (0000-0002-7062-2177)*: revision of the manuscript and intellectual concept. EBC: critical analysis of the intellectual concept and final approval of the manuscript version to be published. *ORCID (Open Researcher and Contributor ID).

\section{REFERENCES}

1. Sunderland $\mathrm{S}$. The intraneural topography of the radial, median, and ulnar nerves. Brain. 1945;68:243-99.

2. Kiloh $\mathrm{LG}$, Nevin $\mathrm{S}$. Isolated neuritis of the anterior interosseous nerve. BMJ. 1952;1(4763):850-1.

3. Ulrich D, Piatkowski A, Pallua N. Anterior interosseous nerve syndrome: retrospective analysis of 14 patients. Arch Orthop Trauma Surg. 2011;131(11):1561-5.

4. Sukegawa K, Suzuki T, Ogawa Y, Kobayashi T, Matsuura Y, Kuniyoshi K. A cadaver study of median-to-radial nerve transfer for radial nerve injuries. $J$ Hand Surg Am. 2016;41(1):20-6.

5. Ray WZ, Mackinnon SE. Clinical outcomes following median to radial nerve transfers. J Hand Surg Am. 2011;36(2):201-83.

6. Lowe JB 3rd, Sem SK, Mackinnon SE. Current approach to radial nerve paralysis. Plast Reconstr Surg. 2002;110(4):1099-113.

7. Tung TH, Mackinnon SE. Nerve transfers: indications, techniques, and outcomes. J Hand Surg Am. 2010;35(2):332-41.

8. Babiloni C, Vecchio F, Babiloni F, Brunelli GA, Carducci F, Cincotti F, et al. Coupling between "hand" primary sensorimotor cortex and lower limb muscles after ulnar nerve surgical transfer in paraplegia. Behav Neurosci. 2004;118(1):214-22.

9. Bach-y-Rita P. Brain plasticity as a basis for recovery of function in humans. Neuropsychologia. 1990;28(6):547-54

10. García-López A, Fernández E, Martínez F. Transfer of brachioradialis motor branch to the anterior interosseous nerve in C8-T1 brachial plexus palsy. An anatomic study. Microsurgery. 2013;33(4):97-300.

11. Bertelli JA. Transfer of the radial nerve branch to the extensor carpi radialis brevis to the anterior interosseous nerve to reconstruct thumb and finger flexion. J Hand Surg. 2015;40(2):323-8.
12. Murphy RK, Ray WZ, Mackinnon SE. Repair of a median nerve transection injury using multiple nerve transfers, with long-term functional recovery. J Neurosurg. 2012;117(5):886-9.

13. Bertelli JA, Mendes Lehm VL, Tacca CP, Winkelmann Duarte EC, Ghizoni MF, Duarte $\mathrm{H}$. Transfer of the distal terminal motor branch of the extensor carpi radialis brevis to the nerve of the flexor pollicis longus. Neurosurgery. 2012;70(4):1011-6; discussion 1011-6.

14. Soldado F, Bertelli JA, Ghizoni MF. High median nerve injury: motor and sensory nerve transfers to restore function. Hand Clin. 2016;32(2):209-17.

15. Hsiao EC, Fox IK, Tung TH, Mackinnon SE. Motor nerve transfers to restore extrinsic median nerve function: case report. Hand. 2009;4(1):92-7.

16. Abrams RA, Ziets RJ, Lieber RL, Botte MJ. Anatomy of the radial nerve motor branches in the forearm. J Hand Surg. 1997;22(2):232-7.

17. Fuss FK, Wurzl GH. Radial nerve entrapment at the elbow: surgical anatomy. J Hand Surg. 1991;16(4):742-7.

18. Schreiber JJ, Byun DJ, Khair MM, Rosenblatt L, Lee SK, Wolfe SW. Optimal axon counts for brachial plexus nerve transfers to restore elbow flexion. Plast Reconstr Surg. 2015;135(1):135e-41e.

19. De Medinaceli L, editor. Cell surgery to repair divided nerves. New York: CASIS-CID; 1994. p. 90-101.

20. Jiang BG, Yin XF, Zhang DY, Fu ZG, Zhang HB. Maximum number of collaterals developed by one axon during peripheral nerve regeneration and the influence of that number on reinnervation effects. Eur Neurol. 2007;58(1):12-20.

21. Brunelli G, Brunelli F. Partial selective denervation in spastic palsies (hyponeurotization). Microsurgery. 1983;4(4):221-4. 